\title{
ATIVIDADE FÍSICA DE AVENTURA NA NATUREZA PARA PESSOAS COM DEFICIÊNCIA
}

Recebido em: 13/01/2018

Aceito em: 08/11/2018

\author{
Darlan Pacheco Silval \\ Instituto Federal da Bahia - IFBA \\ Universidade Estadual de Santa Cruz \\ Ilhéus - Bahia - Brasil \\ Priscilla Ramos Pinto de Freitas Silva ${ }^{2}$ \\ Joslei Viana Souza ${ }^{3}$ \\ Marcial Cotes ${ }^{4}$ \\ Universidade Estadual de Santa Cruz \\ Ilhéus - Bahia - Brasil
}

RESUMO: O objetivo desta pesquisa foi mapear a produção científica em periódicos nacionais da área de Educação Física, entre os anos de 2006 - 2016, relacionadas à prática de atividades físicas de aventura na natureza para pessoas com deficiência. Como instrumento de coleta dos dados, foi realizada uma busca em periódicos nacionais da área de Educação Física, avaliados entre A1 e B2 pela WebQualis (2016), mais a Revista da Associação Brasileira de Atividade Motora Adaptada. Os resultados mostraram um número inexpressivo de pesquisas publicadas envolvendo pessoas com deficiência na prática de atividades físicas de aventura na natureza, ao mesmo tempo em que evidencia que a deficiência não é um impedimento para sua realização. Contudo essas experiências trazem benefícios como oportunizar a este grupo a vivência de atividades diferenciadas do dia a dia, ampliando as opções de lazer, além de potencializar as capacidades dos praticantes.

PALAVRAS CHAVE: Exercício. Natureza. Pessoas com Deficiência.

\footnotetext{
${ }^{1}$ Licenciado em Educação Física pela Universidade Estadual de Santa Cruz (UESC). Especialista em Metodologia em Educação Física e Esporte pela UESC. Especialista em Educação Física Adaptada pela UESC. Atualmente é Professor Efetivo do Instituto Federal da Bahia - Campus Santo Amaro.

${ }^{2}$ Licenciada em Educação Física pela Universidade Estadual de Santa Cruz (UESC). Especialista em Metodologia em Educação Física e Esporte pela UESC. Especialista em Educação Física Adaptada pela UESC. Atualmente é Professora Efetiva da Secretaria Estadual de Educação - Bahia.

3 Pós Doutora em Educação Física Adaptada pela State University of New York, The College at Brockport. Possui Doutorado em Educação Especial pela UFSCar; Mestrado em Educação Física na área de Atividade Física e Adaptação pela UNICAMP; Graduação em Educação Física pela UEL. Atualmente é Professora Titular da UESC; Membro da Sociedade Brasileira de Atividade Motora Adaptada.

${ }^{4}$ Licenciatura Plena em Educação Física e Desportos pela UERJ, Mestre em Meio Ambiente pela UESC e Doutor em Educação Física pela UFSC. É professor Adjunto no Departamento de Ciências da Saúde da UESC e integra o Diretório dos Grupos de Pesquisa do CNPq em: Biologia de Dossel, Núcleo de Pesquisa em Pedagogia do Esporte (NUPPE) e Grupo de Pesquisa em História do Lazer da UFMG.
} 


\section{PHYSICAL ADVENTURE ACTIVITY IN NATURE FOR PEOPLE WITH DISABILITIES}

ABSTRACT: The goal of this research was to map the scientific production in national periodicals of the Physical Education area, between the years 2006 - 2016, related to the practice of physical adventure activities in nature for people with disabilities. As a data collection instrument, a search was conducted in national journals of the Physical Education area, evaluated between A1 and B2 by WebQualis (2016) and the Brazilian Association of Adapted Motor Activity journal. The results showed an inexpressive number of published researches involving people with disabilities in the practice of adventure physical activities in nature, while showing that the disability is not an impediment to their achievement. However, these experiences bring benefits such as giving this group the opportunity to experience different daily activities, expanding leisure options, and enhancing the skills of practitioners.

KEYWORDS: Exercise. Nature. Disabled Persons.

\section{Introdução}

Com a evolução do processo de industrialização, as relações entre o homem e a natureza vêm se transformando de maneira progressiva (THOMAS, 1988). Ao longo da história, esta conexão homem-natureza buscou a compreensão do próprio corpo e uma relação de respeito com o meio natural (RODRIGUES; GONÇALVES JUNIOR, 2009).

No decorrer deste percurso histórico nos deparamos na atualidade com um pensamento, onde a natureza deixa de ser considerada como um mero objeto ou um recurso natural de consumo e exploração, passando a ser inserida no debate social contemporâneo (MUNSTER, 2004). A partir dessa discussão crescente, tornou-se comum uma busca pelo contato com a natureza, principalmente nas atividades de lazer.

A vida contemporânea nos grandes centros urbanos vem vivendo profundas dicotomias, ao diminuir gradativamente o tempo necessário ao lazer e consequentemente às oportunidades de contato com o meio ambiente natural (BRUHNS, 1997; 2010). Neste sentido, Silva e Freitas (2010) entendem que as 
atividades físicas de aventura na natureza possibilitam a reaproximação do ser humano com o meio natural.

Diante disto, participar de vivências junto ao meio natural representa a oportunidade de se assumir riscos controlados, associadas aos sabores de aventura, do ineditismo, as quais são capazes de instigar diversas sensações e percepções (TAHARA; CARNICELLI FILHO; SCHWARTZ, 2006).

Neste contexto, as atividades físicas de aventura na natureza têm se tornado um fenômeno social no debate acadêmico. Estudos apontam a participação da mulher nestas atividades (SCHWARTZ et al., 2016), a percepção dos praticantes (VAZ et al., 2017), a preocupação em estabelecer práticas voltadas ao desenvolvimento sustentável (ROSA; CARVALHINHO; SOARES, 2017), a necessidade de se debater o risco presente nas atividades físicas de aventura na natureza (MOURA; FERREIRA; SOARES, 2016) e a formação (AURICCHIO, 2017) e tipos de aprendizagem destes profissionais (COTES et al., 2017), entre outros. Entretanto ainda são emergentes as discussões referentes ao tema na área acadêmica da Educação Física (MOURA; FERREIRA; SOARES, 2016).

Todavia, mesmo observando, em revistas do extrato superior do WebQualis, um aumento na contemporaneidade de pesquisas direcionadas à compreensão deste fenômeno, foram identificados poucos estudos voltados às pessoas com deficiência entre os anos de 2016-2017. Seguindo este contexto, adaptações são necessárias à prática das atividades físicas de aventura na natureza quando se trata de pessoas com deficiência. Dessa forma, a presente pesquisa faz o questionamento: existem trabalhos publicados em periódicos do WebQualis (2016) nacional que pesquisaram as atividades físicas de aventura na natureza para pessoas com deficiência? 
Diante do exposto, o objetivo geral da pesquisa foi mapear a produção científica em periódicos nacionais, da área de Educação Física avaliados entre A1 e B2 pela WebQualis (2016), além da Revista da Associação Brasileira de Atividade Motora Adaptada (B5) relacionados à prática de atividades físicas de aventura na natureza para pessoas com deficiência (PCD). Para tanto, distinguiu-se quais são as modalidades de atividades físicas de aventura na natureza contempladas, os tipos de deficiência mais assistidos na realização de atividades físicas de aventura na natureza (AFAN) e as adaptações necessárias para a sua realização.

Assim, espera-se contribuir com as discussões no âmbito acadêmico acerca das adaptações para vivenciar as AFAN por PCD, se e quando forem necessárias, bem como a reflexão sobre as iniciativas relatadas academicamente.

\section{Atividades Físicas de Aventura na Natureza (AFAN)}

As AFAN constituem um conjunto de práticas que surgiram nos países desenvolvidos, na década de 1970 (BETRÁN, 2003). Elas se desenvolveram em contato com elementos da natureza nos meios aéreo, aquático e/ou terrestre. As AFAN se consolidaram na atualidade como opção de lazer da sociedade contemporânea na condição de atividades esportivas e como produto de consumo, dentro da esfera do turismo, onde atividades deste tipo estão em significativa expansão (MUNSTER, 2004).

Entretanto ainda há muita discussão entre os autores sobre a nomenclatura referente a tais práticas (PIMENTEL, 2013). Dentre essas nomenclaturas, Betrán e Betrán (1995, p. 6) propõem a utilização da expressão AFAN, definida como:

[...] em conductas motrices como el deslizarse sobre superfícies naturales, en donde el equilibrio para evitar la caída y la velocidad de desplazamiento aprovechando las energías libres de la natureza [...] constituyen los diversos niveles de riesgo controlado em los que se basa la aventura. [...] El placer, la naturaleza, la emoción, la diversión 
y la aventura al alcance de todos pero destilados de manera individualizada, [...].

Estas atividades são estruturadas de forma adequada em termos de estimulação, segurança e motivação, permitindo a superação dos medos; a sensação de liberdade, de ultrapassar limites, de desenvolver o autocontrole e as relações socioafetivas; além de promover a integração do homem com a natureza (BARROSO et al., 2016). Nesta pesquisa, optou-se por utilizar a nomenclatura AFAN para definir um grupo de práticas que usa a natureza como palco (BETRÁN; BETRÁN, 1995).

Corroborando, Vidal (2011) define as AFAN como um conjunto de atividades realizadas na interação com o ambiente natural e com espírito de aventura, contendo um grau de risco controlado, desafio, exploração e descoberta.

Dessa forma, percebe-se o crescimento desse tipo de atividade, o que pode ser manifestado pelo desejo do ser humano de aproximação com o meio natural (SCHWARTZ, 2006). Com o mesmo pensamento, Tahara e Schwartz (2002) afirmaram que as AFAN oferecem a possibilidade de vivenciar sentimentos de prazer, em função de suas características, promovendo, inclusive, a ampliação do senso de limite da liberdade da própria vida.

\section{Pessoas com Deficiência (PCD)}

Com o processo de inclusão social, os debates sobre deficiência estão cada vez mais presentes no contexto das investigações científicas e das políticas públicas, ocupando espaços representativos no panorama nacional e internacional (CORALES; CASTRO, 2016). O fato de o Brasil estar entre os dez países com melhor desempenho no cenário paralímpico mundial gera uma maior visibilidade ao contexto da deficiência, 
assim como avanços conceituais a respeito desta temática (MUNSTER; ALMEIDA, 2016).

Durante séculos, não houve uma terminologia para se referir às $\mathrm{PCD}$, pois os termos difundidos socialmente não consideravam a pessoa como aspecto central. Nesse período, aquele que tinha deficiência era tido como socialmente inútil, um fardo para a família, alguém sem valor profissional (CANTORANI, 2013). Sassaki (2009), em seu estudo, identificou que a utilização dessa terminologia esteve presente em diferentes décadas do século XX e em distintos meios de comunicação: no Decreto Federal $\mathrm{n}^{\mathrm{o}}$ 60.501, de 14/3/67; no Diário Popular, de 21/4/76; na Folha de São Paulo, de 20/07/82; e na IstoÉ, 7/7/99.

Com o passar dos anos e discussões sobre a temática, foram elaboradas diversas terminologias como: pessoa portadora de necessidades especiais; pessoa portadora de deficiência; pessoas com necessidades especiais; portadores de necessidades especiais; pessoas especiais; e, mais recentemente, tem se firmado o termo PCD, a fim de evidenciar a pessoa e não a deficiência (MEDEIROS, DINIZ, 2004; SASSAKI, 2005a; 2009).

Dessa forma, é necessário destacar os tipos de deficiência que, segundo Cardoso (2009), são divididos em quatro grandes grupos: deficiência visual, motora, auditiva e intelectual. Porém a deficiência visual e a auditiva são reconhecidas como sensoriais. Quando há mais de uma deficiência, por exemplo, deficiência visual e auditiva, é denominada de múltiplas deficiências.

A deficiência intelectual caracteriza-se por uma função intelectual acentuadamente abaixo da média, ocorrendo com limitações associadas em duas ou mais das seguintes áreas de habilidades adaptativas aplicáveis: comunicação, cuidados 
pessoais, competências domésticas, habilidades sociais, utilização dos recursos comunitários, autonomia, saúde e segurança, habilidades funcionais para a escola, o trabalho e o lazer (WINNICK, 2004; SASSAKI, 2005b).

Outro tipo de deficiência é visual, que "pode ser compreendida como cegueira e baixa visão, esta última pode acontecer por diversos motivos, tais como, doenças e envelhecimento" (SILVA, 2009, p. 5). Já a deficiência auditiva, popularmente conhecida como surdez, caracteriza-se pelo déficit na capacidade de percepção normal dos sons, que pode ocorrer de forma bilateral, parcial ou total. Sendo considerado surdo o indivíduo cuja audição não é funcional na vida comum, e parcialmente surdo, aquele cuja audição, ainda que deficiente, é funcional com ou sem prótese (BRASIL, 1997).

Por fim, a deficiência física ou motora refere-se a alterações parciais ou completas em um ou mais segmentos corporais (sistema osteoarticular, muscular e nervoso), que ocasionam limitações físicas de graus variáveis (TUDELLA, 2002).

\section{Aventura Inclusiva}

Na década de 1990, Almeida (1995) apontava a necessidade de a Educação Física compreender a importância de atividades realizadas em meio selvagem, como caminhadas ao ar livre, escaladas, equitação e atividades na praia, para o desenvolvimento global de alunos com deficiência visual. Paralelamente a este ideário, cabe estender esse pensamento a todo o tipo de deficiência.

De acordo com Schmidt (2009), dois aspectos podem ser destacados na relação de PCD com as AFAN. O primeiro é o despertar da curiosidade com o meio e os riscos que ele apresenta. O segundo é a manifestação da compreensão de como interagir com o meio. O autor ainda acrescenta que este desenvolvimento global não se restringe apenas 
ao aprendizado do movimento, mas abrange, também, o comportamento em relação ao enfrentamento da vida.

Nascimento e Costa (2017) sugerem que realizar atividades físicas em áreas naturais pode proporcionar o aumento da autoestima e a inclusão de PCD na sociedade. Um aspecto que contribui para a inclusão das PCD nas AFAN é a tecnologia, pois é corresponsável em viabilizar essas atividades nas sociedades contemporâneas. Por outro lado, a tecnologia intervém para gerar condições de segurança no momento da sua prática, contribuindo para a confiabilidade e promoção das atividades. A tecnologia, portanto, configura-se fator de significativa relação com a expansão das AFAN (CANTORANI, 2013).

Por conseguinte, a inclusão no mercado de trabalho e de consumo é parte do resgate da cidadania da PCD (BUZZOLI, 2005; ALVES; NAZARI, 2009). Neste sentido, os autores afirmam que, com a inclusão das PCD, suas necessidades, desejos, anseios e vontades de consumo podem ser exploradas coletivamente, inclusive num ambiente natural.

Entretanto Munster e Almeida (2001) enfatizaram que é imprescindível que não haja simplesmente uma reprodução do sistema social onde se encontram inseridos, mas uma busca por formas próprias de ação e atitude, para a construção de uma sociedade mais humana e inclusiva. Com isso, a PCD é quem deve decidir se precisa ou não se sujeitar a tais AFAN, se vale à pena ou não aderir a essas práticas (MUNSTER; ALMEIDA, 2001).

$\mathrm{Na}$ atualidade, a partir do aumento da autonomia e o resgate da cidadania pelas PCD, agências de turismo oferecem pacotes específicos para atender essa fatia do 
mercado, principalmente em AFAN no meio aquático e terrestre (BUZOLI, 2005; ALVES; NAZARI, 2009).

\section{Metodologia}

A abordagem metodológica do estudo foi a pesquisa qualitativa. Em sua primeira etapa, caracterizou-se como exploratória para uma maior familiaridade com o problema, além de buscar um aprimoramento de ideias ou descobertas de intuições (GIL, 2002). Foi utilizada a pesquisa teórica de caráter bibliográfico para identificar os artigos, com o propósito de aprimoramento do conteúdo e aprofundamento do tema adotado (GIL, 2002).

Como instrumento de coleta dos dados, realizou-se uma busca por periódicos nacionais da área de Educação Física avaliados entre A1 e B2 pela WebQualis (2016), além da Revista da Associação Brasileira de Atividade Motora Adaptada (B5), devido a sua especificidade com o grupo estudado. A opção pela coleta de dados em periódicos nacionais constituiu-se para melhor compreender as pesquisas no contexto nacional, e, para tanto, foram utilizados os descritores: deficiência; aventura; natureza.

O recorte da pesquisa compreendeu os anos de 2006-2016 e o critério de inclusão foi a relação com o objeto do estudo, neste caso a prática de AFAN por PCD. O que não se encontrava dentro deste contexto foi excluído da análise. O procedimento de seleção e análise dos artigos obedeceu às seguintes etapas: a) leitura de todos os títulos e/ou resumos dos artigos publicados; b) levantamento de artigos que tratassem do tema objeto da pesquisa; c) leitura completa dos artigos e; d) construção de categorias analíticas (BARDIN, 2010). 
A partir dos descritores, foi possível identificar inicialmente 215 artigos. Dentre estes, alguns traziam a presença de mais de um descritor no corpo do texto utilizado como referências. Assim os artigos foram separados de acordo com o descritor que apresentava uma relação com o objetivo do estudo.

Numa nova filtragem, foi realizada a leitura dos resumos dos artigos, com a finalidade de identificar os trabalhos relacionados diretamente com o objeto da pesquisa. Após a busca, restaram três estudos nos periódicos: Revista LICERE, Pensar a Prática e a Revista da Associação Brasileira de Atividade Motora Adaptada (SOBAMA).

Importante destacar que muitos dos estudos e pesquisas apresentavam conceitos e informações referentes a um dos descritores selecionados, entretanto não se relacionavam com o objeto da pesquisa, não contribuindo para a análise deste estudo. Como critério de exclusão, havia, por exemplo, trabalhos realizados sobre dificuldade na aprendizagem da matemática - descritor deficiência. Além disto, como processo de avaliação da Pós-Graduação lato sensu em Educação Física Especial, o estudo passou por uma banca com três pareceristas, a fim de contribuir com a pesquisa.

\section{Resultados e Discussão}

Os três estudos encontrados são descritos no Quadro 1, por ordem de classificação na WebQualis (2016). Dessa forma, as discussões realizadas discorrem a partir das informações apresentadas nos estudos selecionados. Com isso, foram construídas as seguintes categorias analíticas: objetivo do estudo; modalidade da AFAN; sujeitos da pesquisa e adaptações. 
Quadro 1: Estudos encontrados sobre Atividades Físicas de Aventura na Natureza (AFAN) para Pessoas com Deficiência (PCD).

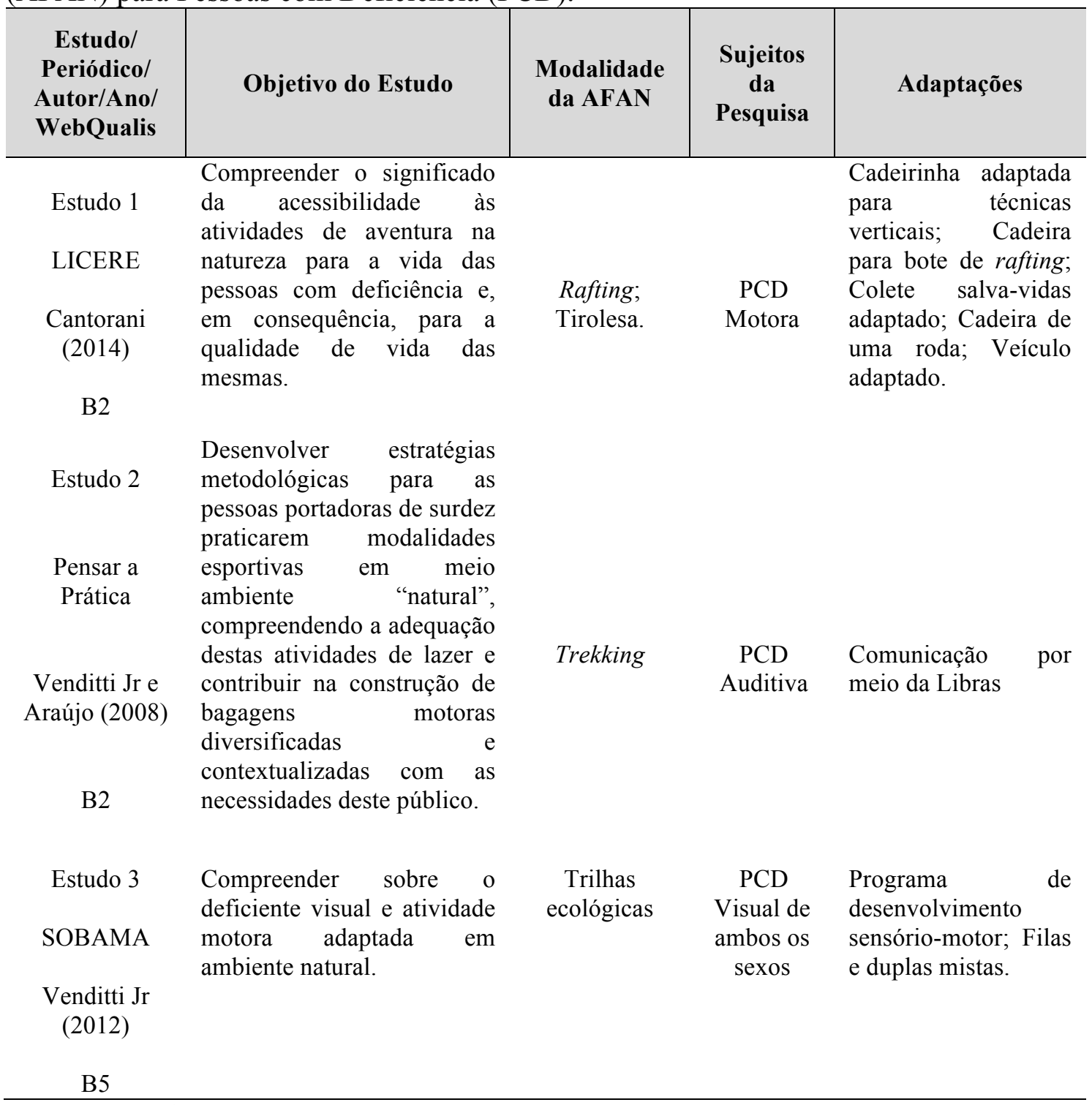

Fonte: Autores da pesquisa.

\section{a) Objetivos dos Estudos}

Em relação aos objetivos, o Estudo 1 (CANTORANI, 2014) preocupou-se em apontar o acesso das PCD às AFAN, bem como suas consequências na qualidade de vida do mesmo, assim como o significado que a acessibilidade apresenta na vida dessas pessoas.

Se tratando de deficiência, a acessibilidade já foi objeto de estudo por Beltrame et al. (2018), onde concluíram que quando a PCD encontra a barreira da acessibilidade a 
apropriação do lazer já se encontra prejudicada. Quando as possibilidades de interação com ambientes diversos são evidentes, contribui para que a PCD migre do papel de coadjuvante para o de protagonista (MENDES; PAULA, 2008).

O Estudo 2 (VENDITTI JÚNIOR; ARAÚJO, 2008) procurou desenvolver estratégias metodológicas, a fim de tornar a prática esportiva regular e saudável para PCD auditiva. Como estratégias metodológicas, Venditti Júnior; Araújo (2008) adotaram inicialmente atividades divididas em quatro grandes grupos: a) avaliação motora inicial; b) atividades básicas e iniciais (desenvolvimento horizontal); c) atividades simulativas (desenvolvimento vertical); e d) atividades complementares. Dentre estas, as atividades simulativas, por exemplo, é uma

Preparação para as práticas reais de campo, utilizando os gestos já assimilados dos surdos e adequando-os para a contextualização nos esportes na natureza de acordo com as especificidades da modalidade esportiva (trekking) (VENDITTI JÚNIOR; ARAÚJO, 2008, p. 273).

Para concretizar propostas de práticas esportivas para PCD é necessário planejar e refletir sobre as estratégias adequadas ao grupo específico. Seabra Júnior e Manzini (2008, p. 6) corroboram esclarecendo que as estratégias de ensino são para uma melhor compreensão dos requisitos necessários para preparar e aplicar tarefas motoras, de acordo com as necessidades do público-alvo em questão.

Na pesquisa de Carvalho (2005) voltada a PCD visual, foi desenvolvida uma proposta metodológica para o ensino da modalidade canionismo (descida de rapel em cachoeiras), preparando os sujeitos do estudo (PCD visual, professores e monitores) para a prática da AFAN, utilizando como estratégia metodológica a fragmentação minuciosa do ensino das técnicas de rapel em cachoeira para PCD visual. O autor afirma que sua preocupação maior foi em decorrência dos riscos inerentes as atividades 
realizadas em altura. $\mathrm{O}$ que ocasionou a necessidade de segmentar à instrução das técnicas do rapel em cachoeira em três partes para obtenção de êxito na aprendizagem.

Carvalho (2005) concluiu que o processo educativo elaborado e a sistematização do ensino das técnicas para PCD visual foi o que proporcionou o sucesso da atividade. Logo, as estratégias pedagógicas podem gerar estímulos que permitam aos participantes da AFAN uma melhor fruição da prática.

O Estudo 3 (VENDITTI JÚNIOR, 2012) buscou compreender sobre o deficiente visual e atividade motora adaptada em ambiente natural. Torna-se evidente que ao proporcionar o aumento dos estímulos à $\mathrm{PCD}$ visual, as chances de enriquecer o repertório motor e com isso promover uma maior adaptação a uma atividade em ambiente natural são maiores (MONTANS; VENDITTI JÚNIOR, 2011).

\section{b) Modalidades das AFAN}

De acordo com as pesquisas encontradas, a modalidade mais contemplada para PCD foi o trekking, presente nos Estudos 2 (VENDITTI JÚNIOR; ARAÚJO, 2008) e 3 (VENDITTI JÚNIOR, 2012). A prática de AFAN, especialmente trekking, necessita do saber se movimentar e, ao mesmo tempo, a percepção do ambiente natural, demandando um conjunto de inter-relações que envolvem os sentidos (visão, audição, tato, olfato, paladar), além de raciocínio rápido e sagacidade, o que pode ser benéfico para estimular alguns destes sentidos durante a vivência das AFAN por PCD. Esta inter-relação é designada por Ingold (2007) de união, durante o caminhar, do deslocamento com a percepção - e que, no decorrer do percurso, constrói-se uma linha por meio dos pontos observados, ou, no caso de PCD, percebidos. 
A percepção, de acordo com Ingold (2000), é a aliciação operacional e exploratória do ser humano por inteiro, onde o corpo e o pensamento são inseparáveis em um mundo rico de estruturas complexas. A PCD, ao fazer uma caminhada em trilha na natureza, estimula os sentidos que não foram objetos da perda de suas funções, pois os olhos permitem tecer uma imagem da paisagem visual, os ouvidos possibilitam estabelecer uma representação sonora, o nariz um panorama olfativo, a boca a experiência do paladar e a pele a sensação tátil. Jarvis $(2012,2015)$ denominaria esse conjunto de sensações de aprendizagem possíveis à PCD de pré-consciente, ou ainda de uma interação constante entre a $\mathrm{PCD}$ e a realidade externa, que possibilita o aparecimento de uma experiência mais elaborada, processo do qual nem sempre a PCD encontra-se consciente. Além da possibilidade de adquirir a experiência/estímulo dos sentidos, por meio do acúmulo de vivências.

Outro aspecto a ser levado em consideração é o financeiro, haja vista que a prática do trekking não necessita de equipamentos, somente de instrução verbal, como aspecto didático-pedagógico, contribuindo para que esta modalidade seja mais acessível do que as demais. O custo é um aspecto que pode dificultar o acesso de PCD, a partir do momento que a empresa prestadora de serviços para este segmento deve adquirir novos equipamentos e/ou modificar aqueles que irão atender as PCD que buscarem a vivência.

\section{c) Sujeitos da pesquisa}

Para a análise do estudo encontrado envolvendo PCD visual (VENDETTI JÚNIOR, 2012 / Estudo 3), é interessante consultar a tese de Carvalho (2005), onde o autor utilizou a modalidade canionismo para pessoas com essa deficiência. Carvalho (2005) afirma que este público cego não apresentou problemas com a questão da altura 
durante a atividade. $\mathrm{O}$ autor entende que a $\mathrm{PCD}$ visual se beneficia sobre os videntes quando a atividade envolve altura. E destaca que ser cego se constitui um paradoxo, pois é "uma vantagem sobre os videntes, como no caso de monitores que ficavam aparentemente "surdos" e completamente atônitos quando eram submetidos às mesmas condições de altura" (CARVALHO, 2005, p. 122).

Ao refletir sobre as considerações de Carvalho (2005), percebe-se que a deficiência visual pode se tornar um facilitador na realização de uma determinada AFAN. Além disto, o conhecimento sobre a deficiência, a constante comunicação e a observação dos profissionais envolvidos na condução da atividade acabam por potencializar as capacidades das PCD durante a prática. Seguindo este raciocínio, é interessante realizar pesquisas para entender quais modalidades de AFAN para PCD são mais adequadas para cada tipo de deficiência.

Entretanto, durante esta pesquisa, foi possível perceber a ausência de trabalhos envolvendo a PCD intelectual, o que sinaliza um desafio, na atualidade, à inclusão deste grupo em futuras pesquisas. Wachtel e Costa (2002) abordam a importância de proporcionar experiências na natureza para PCD intelectual ao utilizar trilhas em excursões guiadas. Para isto é coerente seguir alguns passos: os grupos devem ser pequenos; duração máxima de duas horas; realização de atividades sem pressa; flexibilidade no planejamento; a presença do responsável pelo grupo (WACHTEL; COSTA, 2002).

Em relação ao gênero dos participantes, o Estudo 2 (VENDITTI JUNIOR; ARAÚJO, 2008) aponta a presença de pessoas de ambos os sexos. Schwartz et al. (2016) abordam que a participação de mulheres na prática de AFAN é um crescente, mas que ainda apresenta limitações. O fato de o estudo de Venditti Júnior (2012) 
apresentar um grupo misto de participantes sugere que esse crescente vem contemplando PCD na pesquisa ora em análise.

\section{d) Adaptações necessárias}

Para que as PCD participem efetivamente nas AFAN é necessário adaptações, entende-se que "adaptar não é criar ou remover obstáculos é, sobretudo, encontrar níveis ótimos de participação para qualquer pessoa independentemente dos seus níveis de desempenho" (RODRIGUES, 2006, p. 45).

O Estudo 1 (CANTORANI, 2014) analisa a eficiência dos equipamentos adaptados e as sensações dos praticantes com deficiência motora nas modalidades rafting e tirolesa. Há, por exemplo, a cadeirinha adaptada para técnicas verticais (tirolesa, arborismo e rapel), que foi desenvolvida a partir do equipamento utilizado no parapente, possuindo uma estrutura diferenciada, que "envolve o usuário de uma forma que mesmo uma pessoa que não tenha a sustentação no tronco permanece em uma condição confortável durante a prática" (CANTORANI, 2013, p 186).

Ademais, na prática do rafting por PCD motora é utilizada uma cadeira, inspirada na cadeira do kart, que permite o controle do tronco em pessoas com comprometimento deste segmento, e o participante "não fica preso à cadeira, pois, se o bote virar deve se soltar facilmente" (CANTORANI, 2013, p 187).

Paixão (2012) aponta os recursos biotecnológicos como uma das 10 dimensões que orientam a prática de AFAN. O autor afirma não bastar ter os equipamentos corretos, mas é preciso dominar o manuseio dos mesmos. No que se refere aos cuidados para a prática das AFAN por PCD, Munster (2004) afirma ser necessária à adaptação ao espaço onde será realizada a AFAN, a necessidade de conhecer a disposição dos 
materiais utilizados neste ambiente e a interação destas pessoas com o local em que será realizada a atividade quando possível e necessário for.

A partir disto, Parlebas (1987) já sinalizava que os desafios do meio natural devem ser enfrentados por PCD, pois sua vivência apresenta possibilidades de desenvolvimento no que diz respeito à superação de medos e barreiras. De acordo com Venditti Júnior (2012, p. 2)

[...] estas adaptações e transposições de dificuldades levariam a um desenvolvimento de habilidades aproveitadas no cotidiano do indivíduo, refletindo não somente no seu plano motor e orientacional, mas em suas relações, sua imagem corporal e seu comportamento em planos macro e micro sociais.

É possível identificar que as adaptações existentes à prática do rafting e da tirolesa não necessitaram ser desenvolvidas, pois as mesmas surgem de equipamentos já existentes em outras modalidades esportivas. Assim, as possibilidades de vivências são aumentadas, pois a ausência da necessidade de projetar e construir um equipamento específico acabam por facilitar o acesso e reduzir os custos. Os aspectos a serem destacados é desmitificar o discurso da obrigação de as empresas projetarem e construírem novos equipamentos para que haja a inclusão das $\mathrm{PCD}$ na prática de AFAN; mas, por outro lado, é primordial que esses equipamentos passem por testes de segurança e certificação.

No Estudo 2 (VENDITTI JÚNIOR; ARAÚJO, 2008), os autores buscaram analisar a viabilidade da interação de PCD em ambientes naturais a partir da prática de AFAN. Foi elaborado, com duas pessoas surdas, um programa de desenvolvimento sensório-motor, com 10 encontros programados, com duas horas de duração cada, que foram divididos em quatro grandes grupos: avaliação motora, atividades básicas e iniciais, atividades simulativas e atividades complementares. 
Os autores concluíram que a estruturação de trilhas ecológicas adaptadas aos surdos contribuiu para o desenvolvimento de habilidades motoras e estimulação sensório-perceptiva, além de constatarem a eficiência na resolução de tarefas motoras entre a equipe envolvida e os participantes com deficiência, utilizando a comunicação por meio da Língua Brasileira de Sinais - Libras (VENDITTI JÚNIOR; ARAÚJO, 2008 / Estudo 2).

No entendimento de Venditti Júnior e Araújo (2008) e Pereira Júnior et al. (2016), no que se refere à dificuldade de comunicação, a capacitação em Libras adequada aos profissionais envolvidos diretamente na atividade pode contribuir ao sucesso da AFAN.

Para Tahara e Carnicelli Filho (2009), os profissionais que atuam nas AFAN são essenciais para que as experiências pessoais e educativas estejam ao alcance de todos os participantes, possibilitando desfrutar dos prazeres, das emoções e dos riscos que essas práticas podem oferecer. Carvalho (2005) afirma que, para haver mudanças significativas na introdução de PCD na prática de AFAN, é preciso criar e desenvolver padrões de ensino baseados na pedagogia, desenvolvimento motor e nas particularidades de cada praticante.

Estes aspectos já foram resultados de pesquisas de Paixão; Costa e Gabriel (2009), Paixão e Tucher (2010), Paixão et al. (2011), Paixão (2013; 2015) com instrutores de esportes de aventura para videntes. Os autores analisaram procedimentos referentes à segurança e competência do profissional, haja vista que este deverá aliar uma série de saberes, que incluem domínio da técnica, habilidades adequadas à modalidade que está praticando, conhecimento e emprego da tecnologia de equipamentos, preocupações com a conservação do ambiente, além da capacidade de 
decifrar informações referentes ao ambiente natural (PAIXÃO, 2012). No presente estudo, entende-se que, nas práticas envolvendo pessoas surdas, existe a necessidade da inclusão, neste rol de procedimentos, da formação em Libras.

A partir disto, é possível destacar que, no caso da deficiência auditiva, as adaptações estão relacionadas à forma de comunicação entre os participantes. O que envolve, por exemplo, posicionar-se de frente para a PCD no momento de passar informações, para possibilitar a visão do rosto do profissional pelo praticante surdo, facilitando a compreensão do mesmo. A necessidade de adaptações de materiais não foi percebida no Estudo 2 (VENDITTI JÚNIOR; ARAÚJO, 2008), entretanto é importante preparar a PCD para os imprevistos, simulando possíveis situações que poderão ocorrer durante a prática. Como defende Munster (2004), a antecipação permitirá o contorno das dificuldades que podem surgir nas AFAN.

Foi verificado no Estudo 3 (VENDITTI JÚNIOR, 2012) a possibilidade da interação das PCD visual durante as práticas orientadas de trilhas ecológicas em ambientes naturais. $\mathrm{O}$ autor desenvolveu um programa de pequenos ciclos de trabalho, dividido em três etapas: simular atividades; exercício piloto; e trilhas ecológicas na prática em ambientes naturais.

É recomendado no Estudo 3 (VENDITTI JÚNIOR, 2012) a utilização de fila indiana no decorrer da trilha, indicada para situações de matas mais fechadas com trilhas sinuosas e estreitas. Neste caso, recomenda-se o emprego de pares mistos à locomoção e deslocamento lateral em subidas e/ou descidas de encostas íngremes.

Outra adaptação que pode ocorrer para a realização de trilha ecológica para PCD visual em terreno acidentado, sugerida por Pereira Júnior et al. (2016), é o uso de "barra direcional". Este equipamento de baixo custo e de fácil manuseio permite fazer a 
conexão da pessoa cega com a vidente, onde cada extremidade fica na mão de uma pessoa, facilitando o direcionamento e a comunicação da PCD visual com o profissional orientador. Podendo ser utilizado, inclusive, um bastão de caminhada que poderá ter dupla função: como barra direcional e auxílio no apoio/equilíbrio durante a caminhada.

$\mathrm{Na}$ utilização do equipamento denominado de barra direcional, pode-se estabelecer um conjunto de códigos para aprimorar a comunicação nas subidas, descidas, local estreito, galhos baixos, entre outras situações de obstáculos. Estes códigos podem ser emitidos a partir de movimentos previamente definidos e treinados para cada ação, como, por exemplo: circundução, movimento para frente ou para trás, laterais, entre outros.

No decorrer da AFAN, também é imprescindível a utilização de códigos e/ou informações sonoras quando for necessário transpor obstáculos presentes no percurso, ou em qualquer outra situação que requeira a comunicação entre o orientador/condutor da atividade e a PCD visual. Seguindo este pensamento, Nascimento e Costa (2017) descrevem que trilhas interpretativas inclusivas aguçam diversos sentidos durante esta vivência como, por exemplo: o barulho da água; diferença entre os sons emitidos pelos pássaros; a percepção olfativa; as alterações de temperatura, devido à altura das copas das árvores e à densidade da vegetação.

As evidências no presente estudo sugerem que a utilização de programas de pequenos ciclos de trabalho é imprescindível, ao colaborar para que acidentes sejam minimizados. Neste sentido, Munster (2004) confirma e esclarece que, para a PCD visual, aprender a cair é uma lição importante, caso ocorra esta situação, para saber agir e diminuir suas consequências; além do uso de óculos de proteção durante todo o 
percurso. Desta forma, não se pode deixar de considerar, assim como ocorre para videntes, a importância dos Equipamentos de Proteção Individual (EPI).

Outro aspecto que devemos considerar é o acesso facilitado à aquisição de equipamentos. As PCD podem acabar por adquirir o que for necessário para se equipar, visando à prática de determinada modalidade de AFAN. Neste sentido, a acessibilidade na realização de AFAN tem evoluído devido à tecnologia empregada na segurança dessas atividades, haja vista as adaptações dos produtos, permitindo a prática das PCD (BRASIL, 2008; 2009)

Não obstante, Cantorani (2013, p. 85) afirma:

A relação entre as atividades de aventura e a sociedade hodierna, neste ponto em específico, é aquela estabelecida pelo avanço tecnológico. Esse avanço tecnológico, além do fato de permitir que pessoas não esportistas vivenciem a experiência de praticar atividades de aventura, permite também, hoje, que PCDs também vivenciem essa experiência.

O processo de evolução industrial das novas tecnologias no que concerne aos EPI, os tipos e modelos de cadeiras de rodas, as próteses - que na atualidade são personalizadas e funcionais -, os óculos para baixa visão, os aparelhos auditivos, dentre outros, têm viabilizado a prática de AFAN por PCD e contribuído para a inclusão deste grupo na sociedade. Esta realidade diminui lacunas à participação das PCD nessas atividades, de forma gradual, de acordo com o conhecimento que vem sendo produzido na área.

Assim, a participação de PCD em AFAN tem tomado um crescente e deve ser vista como normal e benéfica para essa parcela da sociedade (CANTORANI, 2013). É importante estar atento às adaptações necessárias para cada modalidade, que acaba por reduzir a limitação gerada pela deficiência, contribuindo para um melhor proveito da atividade realizada. Do mesmo modo, essas vivências podem permitir que as PCD 
adquirissem valores, conhecimentos e habilidades que podem gerar atitudes voltadas para uma conscientização acerca do ambiente em que vive.

\section{Considerações Finais}

Diante do exposto, o objetivo geral da pesquisa foi mapear a produção científica em periódicos nacionais, da área de Educação Física avaliados entre A1 e B2 pela WebQualis (2016), além da Revista da Associação Brasileira de Atividade Motora Adaptada (B5), relacionadas à prática de AFAN para PCD. Os dados do presente estudo sugerem, pelas iniciativas relatadas, um número inexpressivo, de pesquisas publicadas envolvendo PCD na prática de AFAN. Mas, ao mesmo tempo, ficou evidenciado que a deficiência não é um impedimento à sua prática, além de apontar que trilhas na natureza são de baixo custo operacional por não necessitar da aquisição de equipamentos elaborados para a sua prática.

A valorização, na atualidade, do meio natural tem contribuído para o aumento da procura pela AFAN por PCD, pois é perceptível que o contato com a natureza contribui para a formação holística do indivíduo, estimula os sentidos e oportuniza a vivência de sensações e emoções provenientes da relação com o meio natural.

As PCD têm ocupado novos espaços, e entre eles o meio natural, pouco explorado por este grupo social. Do mesmo modo, as empresas e profissionais têm buscado preencher esta lacuna, possibilitando que as PCD tirem benefícios desta relação com a natureza.

Além disto, o caráter didático-pedagógico presente na prática de AFAN se mostrou essencial para que ocorra um aproveitamento satisfatório do que se é proposto. Porém, apesar desta importância, não foi identificado nenhum trabalho, envolvendo 
PCD e AFAN, relacionando-o ao ambiente escolar, o que poderia contribuir para a formação do aluno, permitindo a discussão da inclusão por meio do ambiente natural e o aumento das PCD praticando essas atividades. Outro aspecto não menos importante, percebido pelos autores desta investigação, é a ausência de pesquisas que analise e relacione as modalidades mais indicadas aos tipos de deficiências.

Embora o Brasil tenha sediado os Jogos Paralímpicos de 2016, estar entre os dez primeiros países ranqueados no cenário mundial e ter uma diversidade de áreas naturais propícias para a prática de $\mathrm{AFAN}$, de acesso relativamente fácil, estes fatores não resultaram em um maior número de publicações acadêmicas.

Contudo esperamos contribuir com as discussões acerca da prática de AFAN por PCD, ao considerar que a temática é pouco explorada no meio acadêmico, e ao expor como as adaptações podem colaborar para uma melhor fruição das PCD nas AFAN.

Este estudo sugere a necessidade de pesquisas com o propósito de identificar a lacuna envolvendo PCD intelectual e AFAN, indicando um campo de investigação ainda pouco explorado. Deste modo, poderão compreender melhor o porquê da presença de algumas modalidades e outras não, o que poderá possibilitar a adesão de mais PCD na prática de AFAN. Assim, as diferenças serão tratadas com igualdade, e as dificuldades de cada um serão respeitadas, independentemente de suas limitações.

É importante ressaltar que a formação dos profissionais envolvidos e o caráter didático-pedagógico na realização das AFAN por PCD são aspectos que apresentaram resultados positivos em todas as pesquisas encontradas. O envolvimento com esse conjunto de práticas na natureza poderá caracterizar uma experiência fértil para o fortalecimento das relações da PCD com o outro na sociedade e contribuir para a autonomia dos praticantes, além de colaborar com os aspectos de sustentabilidade ao 
realizar abordagens de educação ambiental em áreas naturais, quando essas práticas se tornarem mais acessíveis.

\section{REFERÊNCIAS}

ALMEIDA, J. J. G. D. Estratégias para a aprendizagem esportiva: uma abordagem pedagógica da atividade motora para cegos e deficientes visuais. 1995. $176 \mathrm{f}$. Tese (Doutorado em Educação Física) - Faculdade de Educação Física. Universidade Estadual de Campinas. Campinas, SP. 1995.

ALVES, L. S.; NAZARI, J. Atividades de Aventura e deficiência: limites e possibilidades. EFDeportes.com, Revista Digital Buenos Aires, ano 14, n. 138, 2009. Disponível em: http://www.efdeportes.com/efd138/atividades-de-aventura-edeficiencia.htm. Acesso em: 12 dez. 2016.

AURICCHIO, J. R. Formação dos profissionais da cidade de Socorro - SP em atividades de aventura no âmbito do lazer. Licere, Belo Horizonte, v.20, n.1, mar. 2017.

BARDIN, L. Análise de Conteúdo. Tradução de Luís A. Reto; Augusto Pinheiro. 5. ed. Lisboa: Edições 70, 2010.

BARROSO, M. et al. Uma "aventura inclusiva" - atividades de natureza e aventura para pessoas com deficiência. Revista UIIPS, Portugal: Rio Maior, n. 01, p. 250-256, 2016.

BELTRAME, A. L. N. et al. A Cidade, O Lazer e a Pessoa com Deficiência: entre a invisibilidade e a emergência da participação social. Licere, Belo Horizonte, v.21, n.2, jun. 2018.

BETRÁN, J. O. Rumo a um novo conceito de ócio ativo e turismo na Espanha: as atividades físicas de aventura na natureza. In: MARINHO, A.; BRUHNS, H. T. Turismo, lazer e natureza. São Paulo: Manole, 2003. p.157-202.

BETRÁN, A. O.; BETRÁN, J. O. Análisis de las actividades físicas de aventura en la naturaleza. Apunts: educación física y deportes, Barcelona, n.41, p.100-1107, 1995.

BRASIL. Deficiência auditiva, Secretaria de Educação Especial. Série Atualidades Pedagógicas. Brasília: MEC/SEESP, 1997.

BRASIL, M. D. T. Turismo de Aventura: orientações básicas. Brasília: Ministério do Turismo, 2008.

Turismo Acessível: Bem Atender no Turismo de Aventura Adaptada. Brasília: Ministério do Turismo, 2009.

BRUHNS, H. T. Lazer e Meio Ambiente: corpos buscando o verde e a aventura. Revista Brasileira de Ciências do Esporte, v. 18, n. 2, p. 86-91, 1997. 
BRUHNS, H. T. O ecoturismo e o mito da natureza intocada. Acta Scientiarum Human and Social Sciences, Maringá, v. 32, n. 2, p. 157-164, 2010.

BUZOLI, A. Deficientes visuais nas trilhas de ecoturismo. III Colóquio De Turismo Os Territórios Turísticos no Estado de Goiás, Universidade Federal de Goiás, 2005.

CANTORANI, J. R. H. Lazer nas atividades de aventura na natureza e qualidade de vida para pessoas com deficiência: um estudo a partir do caso da cidade de Socorro-SP. 2013. 259 f. Tese (Doutorado em Educação Física) - Faculdade de Educação Física. Universidade Estadual de Campinas. Campinas, SP. 2013.

. Lazer nas atividades de aventura na natureza e qualidade de vida para pessoas com deficiência: um estudo a partir do caso da cidade de Socorro-SP. Licere, Belo Horizonte, v.17, n.1, mar. 2014.

CARDOSO, J. S. A inclusão de alunos com deficiência nas aulas de educação física na rede municipal de ensino de Ilhéus-Bahia. Trabalho de conclusão de curso Universidade Estadual de Santa Cruz. Ilhéus, 2009.

CARVALHO, A. J. S. de. Esportes na natureza: estratégias de ensino do Canionismo para pessoas com deficiência visual. Tese (Doutorado em Educação Física) - Faculdade de Educação Física. Universidade Estadual de Campinas. Campinas, SP. 2005.

CORALES, C. M. S.; CASTRO, E. D. de. Passear e participar: o lazer ampliando a circulação social de pessoas com deficiência. Licere, Belo Horizonte, v.19, n.3, set. 2016.

COTES, M. et al. Aprendizagem formal, não formal e informal: como condutores de dois parques nacionais estabelecem seu tirocínio. Movimento, Porto Alegre, v. 23, n. 4, p. 1381-1394, out./dez. 2017.

GIL, A. C. Como elaborar projetos de pesquisa. São Paulo: Atlas, 2002.

INGOLD, T. Perception of the Environment. Essays in Livelihood, Dwelling and Skill. New York: Routledge, 2000.

Lines: a brief history. London: Routledge, 2007.

JARVIS, P. Learning from Everyday Life, HSSRP, v. 1, n. 1, p. 1-20, 2012.

Aprendizagem Humana: implícita e explícita. Educação \& Realidade, Porto Alegre, v. 40, n. 3, p. 809-825, 2015.

MEDEIROS, M.; DINIZ, D. Envelhecimento e deficiência. In: Camarano, A. A. (Org.). Os Novos Idosos Brasileiros: Muito Além dos 60?Rio de Janeiro: IPEA, 2004.

MENDES, B. C.; PAULA, N. M. A Hospitalidade, o Turismo e a Inclusão Social para Cadeirantes. Turismo em Análise, v. 19, n.2, 2008. 
MONTANS, D. F.; VENDITTI JÚNIOR, R. Atividade motora adaptada para deficientes visuais: experiência com natação em instituições inclusivas. EFDeportes.com, Revista Digital. Buenos Aires, Ano 15, No 152, 2011.

MOURA, D. L.; FERREIRA, M. S.; SOARES, A. J. G. Compreender, relativizar e desconstruir: os discursos do risco na produção acadêmica sobre esportes de aventura. Licere, Belo Horizonte, v. 19, n. 1, p. 1-20, 2016.

MUNSTER, M. A. V. Esportes na natureza e deficiência visual: uma abordagem pedagógica. 2004. 311 f. Tese (Doutorado em Educação Física) - Faculdade de Educação Física. Universidade Estadual de Campinas. Campinas, SP. 2004.

; ALMEIDA, J. J. G. Esportes na natureza: possibilidades para o deficiente visual. In: SOCIEDADE BRASILEIRA DE ATIVIDADE MOTORA ADAPTADA. Temas em Educação Física Adaptada. Curitiba: SOBAMA, p. 20-26, 2001.

; __ Esporte, lazer e deficiência: avanços e retrocessos no município de São Carlos. Revista da Sobama, Marília, v. 17, n. 1, p. 19-24, jan./jun. 2016.

NASCIMENTO, S. R.; COSTA, V. C. Avaliação da Educação Ambiental em trilhas interpretativas inclusivas no Estado do Rio de Janeiro. Revista Brasileira de Ecoturismo, São Paulo, v. 10, n. 1, p. 171-185, 2017.

PAIXÃO, J. A. Entre a aventura e o risco: formação e atuação profissional de instrutores de esporte de aventura no estado de Minas Gerais. Revista Mackenzie de Educação Física e Esporte, v. 14, p. 257-271, 2015.

. Training and Professional Performance of Radical Sport Instructors. International Journal of Sports Science, v. 3, n.6, p. 198-203, 2013.

O instrutor de esporte de aventura no Brasil e os saberes necessários a sua atuação profissional. Curitiba: CRV, 2012.

et al. Risco e aventura no esporte na percepção do instrutor. Psicologia \& Sociedade, v.23, n. 2, p. 415-425, 2011.

.; TUCHER, G. Risco e aventura por entre as montanhas de Minas: a formação do profissional de esporte de aventura. Pensar a Prática, Goiânia, v. 13, n. 3, p. 1-19, 2010 .

.; COSTA, V. L. M.; GABRIEL, R. E. C. D. Esporte de aventura e ambiente natural: dimensão preservacional na sociedade de consumo. Motriz, v.15, n.2, p. 367$373,2009$.

PARLEBAS, P. Perspectivas para uma Educación Física moderna. Málaga: UNISPORT, 1987.

PEREIRA JÚNIOR, D. et al. Aventura Adaptada: um roteiro turístico e cultural. São Paulo: Áurea Editora, 2016. 
PIMENTEL, G. G. A. Esportes na natureza e atividades de aventura: uma terminologia aporética. Revista Brasileira de Ciências do Esporte, Florianópolis, v. 35, n. 3, p. 687-700, jul./set. 2013.

RODRIGUES, C.; GONÇALVES JUNIOR, L. Ecomotricidade: sinergia entre educação ambiental, motricidade humana e pedagogia dialógica. Motriz, Rio Claro, v. 15, n. 4, p. 987-995, 2009.

RODRIGUES, D. (Org.) As dimensões de adaptação de atividades motoras. In: RODRIGUES, D. (Org.) Atividade motora adaptada: alegria do corpo. São Paulo, Artes Médicas, 2006.

ROSA. P. F.; CARVALHINHO, L. A. D.; SOARES, J. A. P. O desporto de natureza e o desenvolvimento sustentável: perspectivas de desenvolvimento e governança. Movimento, Porto Alegre, v. 23, n. 1, p. 419-436, jan./mar. 2017.

SASSAKI, R. K. Atualizações semânticas na inclusão de pessoas: deficiência mental ou intelectual? Doença ou transtorno mental? Revista Nacional de Reabilitação, São Paulo, ano IX, n. 43, p. 9-10, 2005a.

SASSAKI, R. K. Como chamar as pessoas que tem deficiência? In: Anais I Seminário de Práticas de Inclusão no Ensino Superior. Piracicaba: UNIMEP, 17-18 de março de 2009.

SASSAKI, R. K. Terminologia sobre deficiência na era da inclusão. Rede SACI, 2005b. Disponível em: http://www.mp.pe.gov.br/uploads/zEEORSTek4V . Acesso em: 10 jan. 2017.

SCHMIDT, A. A. Canoagem e deficiência intelectual: navegar é (im)preciso. In: III Congresso Brasileiro de Atividades de Aventuras: Mercado de Trabalho e Inclusão, Mucugê-BA, 2009.

SCHWARTZ, G. M. Aventuras na Natureza: consolidando significados. Jundiaí, SP: Fontoura Editora, 2006.

et al. Estratégias de participação da mulher nos esportes de aventura. Rev. Bras. Ciênc. Esporte, v. 38, n. 2, p. 156-162, 2016.

SEABRA JÚNIOR, M. O.; MANZINI E. J. Recursos e estratégias para o ensino do aluno com deficiência visual na atividade física adaptada. Marília: ABPEE, 208

SILVA, A. S. A inclusão dos alunos com deficiência nas aulas de educação física na rede estadual de ensino de Itabuna-Ba. 2009. Trabalho de conclusão de curso Universidade Estadual de Santa Cruz. Ilhéus, 2009.

SILVA, P. P. C; FREITAS, C. M. S. M. Emoções e riscos nas práticas na natureza: uma revisão sistemática. Motriz, Rio Claro, v. 16, n.1, p. 221-230, 2010. 
TAHARA, A.; CARNICELLI FILHO, S. Atividades físicas de aventura na natureza (AFAN) e academias de ginástica: motivos de aderência e benefícios advindos da prática. Movimento, v. 15, n. 3, p. 187-208, jul./set. 2009.

TAHARA, A. K.; CARNICELLI FILHO, S.; SCHWARTZ, G. M. Meio ambiente e atividades de aventura: significados de participação. Motriz, Rio Claro, v.12 n.1 p.5964, jan./abr. 2006.

.; SCHWARTZ, G. M. Atividades de aventura: análise da produção acadêmica do ENAREL. Licere, v.5, n.1, p. 50-58, 2002.

THOMAS, K. O homem e o mundo natural: Mudanças de atitudes em relação às plantas e aos animais, 1500-1800. Tradução João Roberto Martins Filho. São Paulo: Companhia das Letras, 1988.

TUDELlA, E. Deficiência física. In: PALHARES, M. S.; MARINS, S. C. (Org.). Escola inclusiva. São Carlos: EdFSCar, 2002. p. 155-177.

VAZ, J. M. et al. Percepção de competências profissionais de instrutores de atividades de aventura na natureza atuantes em Florianópolis/SC. Movimento, Porto Alegre, v. 23, n. 1, p. 295-310, jan./mar. 2017.

VENDITTI JÚNIOR, R., ARAÚJO, P. F. de. Trilhas ecológicas com orientação para pessoas surdas. Pensar a Prática, v. 11 n.3 p.269-280, set./dez. 2008.

O ambiente natural como agente facilitador do desenvolvimento sensorial e motor para as pessoas com deficiência visual. Revista da Sobama, Marília, v. 13, n. 2, p. 49-56, jul./dez. 2012.

VIDAL, A. P. R. M. A segurança em actividades de ar livre e de aventura. Dissertação (Mestrado em Ensino da Educação Física no Ensino Básico e Secundário) Faculdade de Educação Física e Desposto. Universidade Lusófona de Humanidades e Tecnologias. Lisboa, 2011.

WACHTEL, G.; COSTA, C. M. R. Brincando e aprendendo com a mata: manual para excursões guiadas. Projeto Doces Matas. Belo Horizonte, 2002.

WINNICK, J. P. Educação Física e Esportes Adaptados. Barueri, São Paulo: Manole, 2004. p. 555.

\section{Endereço dos Autores:}

Darlan Pacheco Silva

Rua Santa Cruz, Bairro Vila das Dores, $n^{\circ} 453$

Itabuna - BA - 45.604-802

Endereço Eletrônico: darlan.ef@hotmail.com 
Darlan Pacheco Silva, Atividade Física de Aventura na Natureza para Pessoas com Deficiência

Priscilla Ramos P. de Freitas Silva,

Joslei Viana Souza e Marcial Cotes

Priscilla Ramos Pinto de Freitas Silva

Rua Santa Cruz, Bairro Vila das Dores, ${ }^{\circ} 453$

Itabuna - BA - 45.604-802

Endereço Eletrônico: priscillaprf@hotmail.com

Joslei Viana de Souza

Campus Soane Nazaré de Andrade - Rod. Jorge Amado, km 16 - Salobrinho Ilhéus - BA - 45.662-900

Endereço Eletrônico: josleisouza31@gmail.com

Marcial Cotes

Campus Soane Nazaré de Andrade - Rod. Jorge Amado, km 16 - Salobrinho Ilhéus - BA - 45.662-900

Endereço Eletrônico: mcotes@uesc.br 